\title{
The deep blue day is decreasing in China
}

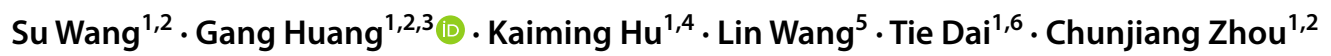

Received: 27 June 2021 / Accepted: 11 December 2021 / Published online: 22 January 2022

(c) The Author(s), under exclusive licence to Springer-Verlag GmbH Austria, part of Springer Nature 2021

\begin{abstract}
The deep blue sky is an indicator of a lower concentration of aerosols and a cloudless sky. With increasing human emissions, a trend towards days with fewer deep blue skies might indicate a decline in a good living environment for humans. This study investigates the long-term changes of the deep blue sky in China from 1980 to 2018. Due to a lack of direct measurements, we use atmospheric visibility and low cloud cover to classify blue sky days into three grades: light blue day, medium blue day, and deep blue day. Climatologically, annual deep blue days increase from southeast China to northwest China, with the maximum number in Xinjiang and eastern Inner Mongolia and the minimum number in western Qinghai and southern Hebei. From 1980 to 2018, annual deep blue days show a prominent decreasing trend in most of China, with area-mean annual deep blue days decreasing by -0.48 days per year $(\mathrm{d} / \mathrm{y})$ in China, and the variation becomes more obvious after 2013. The maximum decreasing trend is observed in eastern China. The most prominent decreases of deep blue days are seen in winter. Both air pollution and the change in meteorological conditions contribute to the decrease of wintertime deep blue days in China. Specifically, the decrease in surface wind speed hinders the cleaning of air by winds, the increase in surface air temperature, and decrease in relative humidity is favorable for low cloud increase, and the increasing emission of pollution reduces atmospheric visibility.
\end{abstract}

Gang Huang

hg@mail.iap.ac.cn

$\triangle$ Kaiming $\mathrm{Hu}$

hkm@mail.iap.ac.cn

1 State Key Laboratory of Numerical Modeling for Atmospheric Sciences and Geophysical Fluid Dynamics, Institute of Atmospheric Physics, Chinese Academy of Sciences, Beijing 100029, China

2 University of Chinese Academy of Sciences, Beijing 100049, China

3 Laboratory for Regional Oceanography and Numerical Modeling, Qingdao National Laboratory for Marine Science and Technology, Qingdao 266237, China

4 Center for Monsoon System Research, Institute of Atmospheric Physics, Chinese Academy of Sciences, Beijing, China

5 Key Laboratory of Regional Climate-Environment for Temperate East Asia, Institute of Atmospheric Physics, Chinese Academy of Sciences, Beijing 100029, China

6 Collaborative Innovation Center on Forecast and Evaluation of Meteorological Disasters/Key Laboratory of Meteorological Disaster of Ministry of Education, Nanjing University of Information Science and Technology, Nanjing, China

\section{Introduction}

With the improvement in living standards, there is a growing desire for a better atmospheric environment and more clear blue skies. Traditionally, a sunny day with few clouds means blue sky day. However, with increasing anthropogenic emissions, the sky might be less or not blue even when the weather condition is "sunny (defined by cloud cover)" (Fast et al. 2006; Yang et al. 2011; Lin et al. 2012; Li et al. 2016a). On the other hand, fewer air pollutions do not directly bring in more blue skies, considering days with higher cloud cover or precipitation. The inconsistency between dropping PM and unchanged low visibility events (Ding et al. 2016) can be seen even during the COVID-19 lockdown period (Huang et al. 2020b; Huang et al. 2020c; Liu et al. 2020). All mentioned above try to convey the non-synergy correlation between air pollution and blue days when considering the unfavorable meteorological conditions dominated by largescale synoptic circulation (Bei et al. 2020a). Thus, there are reasons to believe that "sunny" or "clean" may not be sufficient for a blue sky.

A series of heavy air-pollution events in the early 2010 s in China have raised people's strong desire for better air quality as well as more blue skies (Zhang et al. 2014; Zhang 
et al. 2015). The State Council of China has issued a series of strict anti-pollution control, such as the Air Pollution Prevention and Control Action Plan (China State Council 2013) and Blue-Sky Protection Campaign (China State Council 2018). However, there may be a discrepancy about whether clean actions have brought in more blue days by studies focusing on air quality or cloud cover (Zhang et al. 2019c; Bei et al. 2020b; Dai et al. 2020). Therefore, lacking direct index, it is still a challenge to understand the change of blue sky days in China and its underlying mechanism.

The first challenge is how to define a blue sky day. The occurrence of the blue sky depends not only on meteorological conditions but also on environmental conditions. First, a blue sky day should be a sunny day, which can be identified by low cloud cover and precipitation records. Second, a blue sky day should have clean air. Previous studies show that good air quality can be represented by high atmospheric visibility in the long term (Wu 2004; Ma et al. 2014; Zhang et al. 2014; Liu et al. 2017). Thus, our previous study (Wang et al. 2019) defined a blue sky day via the following criteria: the days with no rain, low cloud cover $\leq 75$ th percentile, and the dry visibility in 14:00 $\geq 15 \mathrm{~km}$.

However, the above definition does not tell the degree of blue of a blue sky day. In the real world, the gradations of the blue sky days are different from each other via presenting different RGB values (Fig. S1), which is dominated by the discrepancy between meteorology and the environment. A continuous deep blue days during the APEC (Asia-Pacific Economic Cooperation) conference in Beijing during December 2014 (Liu et al. 2016; Sun et al. 2016; Zhang et al. 2016; $\mathrm{Xu}$ et al. 2018) attract people' attention around the world. Thus, classifying the blue days into different degrees will help us understand the change of blue days better.

The second challenge is how to assess the relative contributions of meteorological conditions and environmental factors to the change in the blue sky days. Observed evidence (Panmao et al. 1999; Alexander et al. 2006; Zhou et al. 2009; Hu et al. 2013; Easterling et al. 2019) shows that East Asia has experienced prominent changes in rainfall, temperature, and atmospheric circulation during recent decades. Meantime, with the development of industry, the emissions of aerosol have also increased significantly (Kato and Akimoto 2007; Meinshausen et al. 2009; Zhang and Wei 2014; Millar et al. 2017). Many studies show that the changes in meteorological and environmental conditions are responsible for the increase of air pollution events in China during recent decades (Kaiser 2002; Li et al. 2014; Dufour et al. 2015; Dai et al. 2020). For example, the weakened monsoon may increase the aerosol concentrations over eastern China (Zhu et al. 2012; Li et al. 2016b) and amplify persistent haze in Beijing (Li et al. 2016b; Cai et al. 2017). Nevertheless, we still do not know the role of meteorological and environmental factors in blue sky day change in China.
This study aims to creatively classify blue days into 3 grades, analyze their spatial-temporal variations during 1980-2018 in China, and reveal the effect of air pollution prevention plans. The rest of the paper is organized as follows. Section 2 describes the data and methods sued. Section 3 shows evidence for deep blue sky days decrease in China especially in winter and discusses the possible reasons for the change. Section 4 includes a conclusion and some discussions.

The classified blue days could be a direct index to evaluate the efficiency of the pollution prevention and control measures quantitatively in recent years. As life satisfaction and happiness are closely related to deep blue sky (Welsch 2006; Luechinger 2010; Li et al. 2014), this work will help to the construction of people's livelihood. Meanwhile, it could provide a reference to studies on the relationship between weather and disease such as lung cancer and abortion (Pope et al. 2002; Zhang et al. 2019a; Zhang et al. 2019b). Focusing on days suitable for outdoor activities, it also serves the tourist industry and selection of important events. Finally, studying the mechanism behind the deep blue days will be a referee to host mega-events like Olympic Winter Games and implement policies on energy conservation and emission reduction.

\section{Data and methods}

\subsection{Data}

The daily meteorological observation data, including wind speed at $10 \mathrm{~m}$, relative humidity, low cloud cover, and visibility values at 14:00 BJT from 1980 to 2018, were derived from the National Meteorological Information Center of the China Meteorological Administration. The monthly European Centre for Medium-Range Weather Forecasts (ECMWF) Re-Analysis-Interim atmospheric reanalysis data from January 1980 to December 2018 with a horizontal resolution of $0.75^{\circ} \times 0.75^{\circ}$ (Dee et al. 2011) are used in the analysis of climatic conditions for blue sky days. The Community Emissions Data System (CEDS) for historical emissions from 1980 to 2014 ((Hoesly et al. 2018) is used as an auxiliary to study the anthropogenic contribution, which is available from https://github.com/JGCRI/CEDS/.

\subsection{Data quality controls}

To ensure the accuracy and continuity of data used, a series of strict quality controls have been implemented following earlier work (Wang et al. 2019). In particular, as manual visibility measurement is broadly replaced by automated detection techniques around 2013-2015, special treatment is required for visibility records to keep data consistency. To this end, we transform the visibility during the post-2013 period according to the formula below 
(Organization 2008; Pei et al. 2018; Zhang et al. 2020a) to maintain data consistency:

$\frac{\text { VIS auto }}{\text { VIS manual }}=\frac{(1 / k) \times \ln (1 / 0.05)}{(1 / k) \times \ln (1 / 0.02)} \approx 0.766$

where $k$ represents the extinction coefficient, and 0.05 and 0.02 denote the thresholds taken by the automatic and human observer, respectively. The visibility manual $_{\text {and }}$ visibility $_{\text {auto }}$ are the human and instrument measurements of atmospheric visibility, respectively. In the analyses, the maximum of human observing visibility has been set to 30 $\mathrm{km}$ to reduce the discrepancy between the two observed methods. We also use the Standard Normal Homogeneity Test (SNHT) (Alexandersson and Moberg 1997) to verify whether stations exhibit considerable discontinuity in annual average visibility, by which only station observations passing the $99 \%$ confidence level test have been retained. Earlier studies have compared manual and automatic observations (Fan et al. 2017; Chang et al. 2020; Zhang et al. 2020a), and their results reported that although the threshold has been modified during 2013-2015, the continuity of the long-term data is not affected (Yin et al. 2017; Pei et al. 2018; Wang et al. 2020). Recent work demonstrated that this data adjustment can improve the continuity and reliability of visibility data (Zhang et al. 2020a). After quality control, data at 378 monitoring stations remain for further investigation (Fig. 1).

\section{Methods}

\subsection{Classification of blue days}

The classification procedures of blue days are as follows. Following our earlier work that takes the low cloud cover of the individual station into consideration, two thresholds are selected to represent the blue days at different levels. One is the national mean visibility $(21.52 \mathrm{~km})$ in all blue

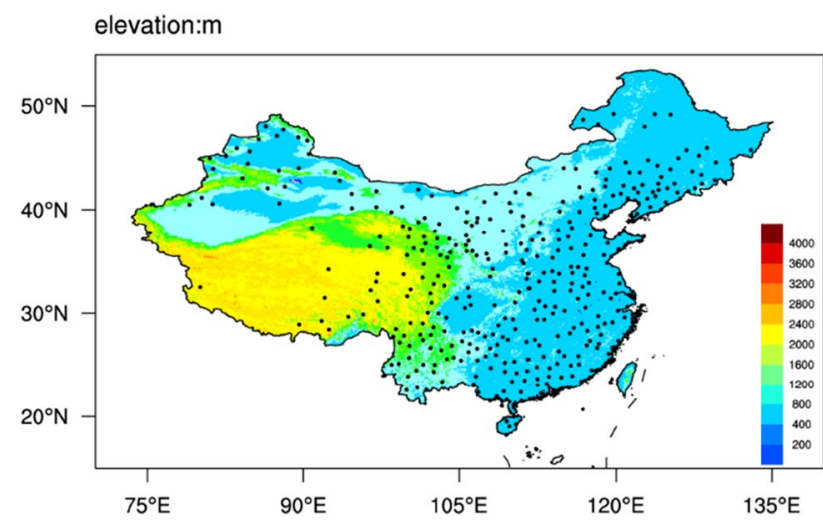

Fig. 1 Location and altitudes of 378 meteorological stations in China days from 1980 to 2018 in China (T1), and the other is the multi-year average value of low cloud cover in blue days at each station (T2). With the defined thresholds, we build two corresponding criteria to check: (1) whether the visibility is larger than T1; (2) whether the low cloud cover is less than T2. Based upon the above two criteria, Chinese blue days (CBDs) can be divided into three categories.

(1) Deep blue: If one day meets both two prerequisites, it is recognized as the deep blue day (CBD3), representing the most desirable rate of blue days for people.

(2) Medium blue: If it fits only one of them, it is termed as medium blue days (CBD2).

(3) Light blue (CBD1): If it satisfies neither of the two prerequisites, it is ranked as the light blue days (CBD1), suggesting that it merely reaches the lowest level: the weakest blue days.

Case studies have been conducted to test the accuracy of the classification. Almost all well-known blue events, such as the APEC blue and Parade blue fall into the CBD3 category (not shown), indicating that our classification is reasonable.

\section{Methods}

A linear-trend analysis is used to reveal the variations of the time series of variables. Pearson correlation, and the standardized multivariate linear regression model (SMLR), and the Student's $t$-test are performed to verify the relationships between CBD and the influencing factors. The SMLR model has been used in many studies to link predictand and predictors to quantify the relative contributions of each variable (Tai et al. 2010; Zhang et al. 2014; Zhai et al. 2019; Pei et al. 2020). By using the SMLR, the standardized regression coefficients (Beta) can be compared among different variables, which represents the percentage of change in CBD with unique variations of each variable if all the other variables are unchanged after removing impacts of units and sample size (Wilks et al. 2006). In this study, the square of Beta is used as the explained variance; the closer this statistic is to $100 \%$, the greater the contributions to the classified CBD.

The Earth System Modeling Framework is used for interpolating data into the $1^{\circ} \times 1^{\circ}$ grid to increase statistical robustness (Jones 1999). Besides, the $K$ index is employed to represent the stratification instability of moist air in the lower and middle troposphere. The equation is as follows (Zhang et al. 2007):

$K=\left(T_{850}-T_{500}\right)+T_{d 850}-\left(T-T_{d}\right)_{700}$. 
where $T$ and $T_{\mathrm{d}}$ represent air temperature and dewpoint, and the subscript numbers show the geopotential height levels.

\section{Results}

\subsection{Climatology and long-term trends of classified Chinese blue days in China}

Figure $2 \mathrm{a}-\mathrm{c}$ illustrate the spatial distribution of the average classified CBD in China during 1980-2018. At nationwide scale, the annual average CBD1-3 in China are 17.83, 82.01, and 62.00 days(d)/year(y), respectively. Basically, CBD1 exhibits a roughly geographic homogeneous pattern throughout the entire country, and the relatively low centers of CBD1 (below 5 days a year) are located in Yunnan, east of Tibet, and Hainan provinces. In contrast, Qinghai and most parts of Tibet share the maximum CBD1 with a value beyond $65 \mathrm{~d} / \mathrm{y}$. Compared to CBD1, the CBD2 tends to increase gradually from about $50 \mathrm{~d} / \mathrm{y}$ in southeast China to more than $80 \mathrm{~d} / \mathrm{y}$ in northwest China. As expected, almost all the low CBD2 centers reside in Southern China due to relatively higher low-cloud cover. The minimum CBD2 center, below $14 \mathrm{~d} / \mathrm{y}$, is located in Hebei province. CBD3 increases from southeast China to northwest China with the maximum number in Xinjiang and eastern Inner Mongolia (over $70 \mathrm{~d} / \mathrm{y}$ ), and the minimum number in western Qinghai and southern Hebei (Fig. 2c, over $13.46 \mathrm{~d} / \mathrm{y}$, and $26.85 \mathrm{~d} / \mathrm{y}$ ).

The temporal evolutions of different CBD anomalies during 1980-2018 are shown in Fig. 2d. Upward trends are identified for CBD, CBD1, and CBD2 at a rate of $0.25,0.34$, and 0.39 days/year (d/y), respectively. Nevertheless, CBD3 is dominated by a declining trend exceeding $-0.48 \mathrm{~d} / \mathrm{y}$, indicating a downward trend since 1980 . Obvious increases of CBD1-2 can be found from 2014 to 2018 , followed by an apparent decreasing CBD3 contemporaneous. This reveals the instant effect of emission controls on increasing CBD1-2 but an insufficient effect on increasing CBD3.

Figure 3 reveals the spatial distribution of trend coefficients with a horizontal resolution of $1^{\circ} \times 1^{\circ}$ in annual mean classified CBD from 1980 to 2018. It is obvious that CBD1 reveals an upward trend in almost $91.28 \%$ of grids (Fig. 3a). The most striking upward trend appears in northwestern China, with a value beyond $1 \mathrm{~d} / \mathrm{y}$. As for CBD2 (Fig. 3b), there is a similar dominant increasing trend over China (over $74.0 \%$ ). Nearly all grids in the south of $38^{\circ} \mathrm{N}$ are dominated by an ascending trend, with a conspicuous center exceeding $0.95 \mathrm{~d} / \mathrm{y}$ in southeastern China (SWC). In contrast, decreasing trends mostly occur in the north of $30^{\circ} \mathrm{N}$, such as western Inner Mongolia, Qinghai, and some stations in northeast China. In contrast to CBD1 and CBD2, apart
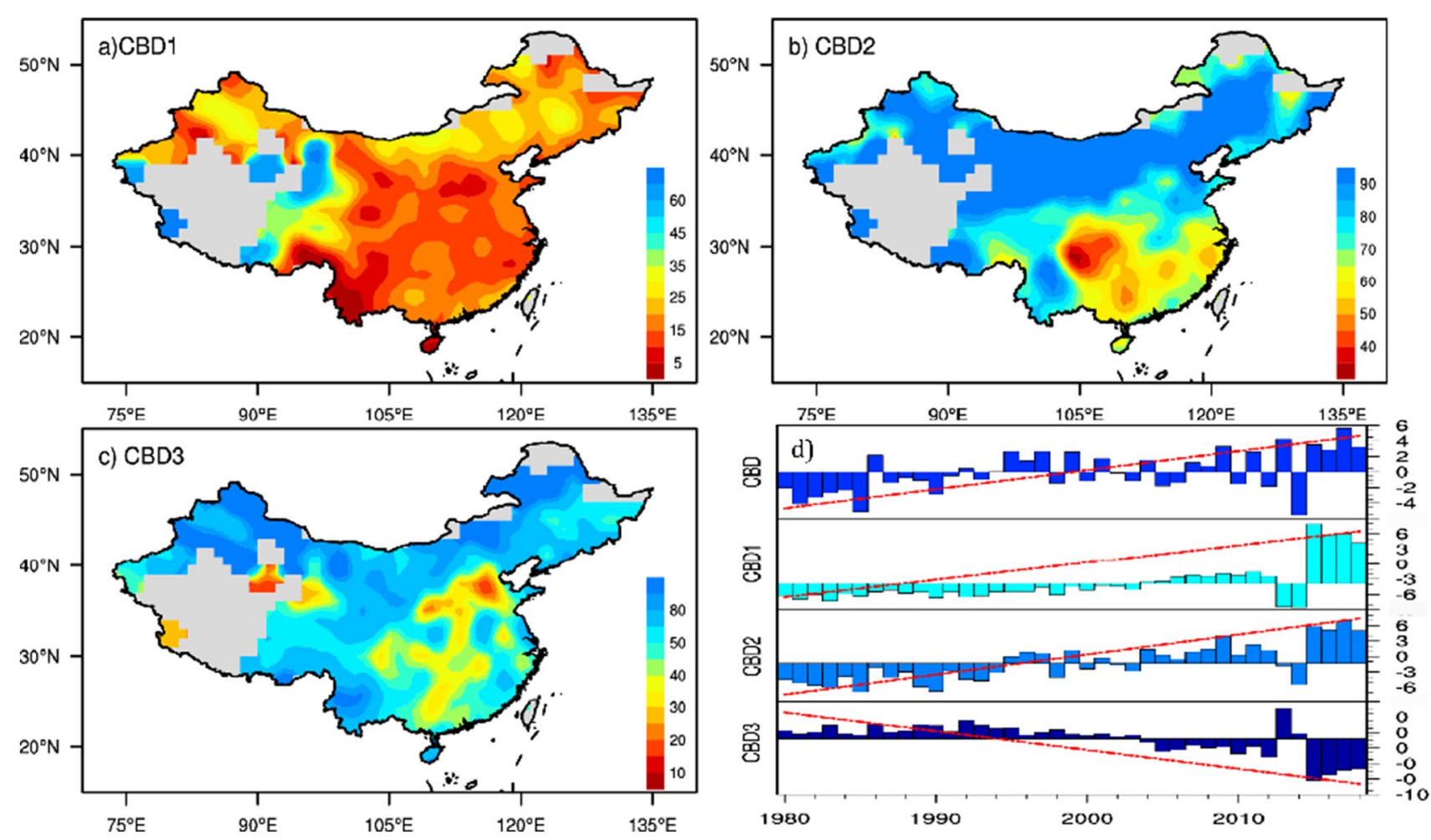

Fig. 2 Spatial distribution of annual mean CBD under different grades in China during 1980-2018 (unit days), (a) CBD1, (b) CBD2, (c) CBD3, and (d) time series of the anomalous CBD in China from 1980 to 2018 (unit days) 


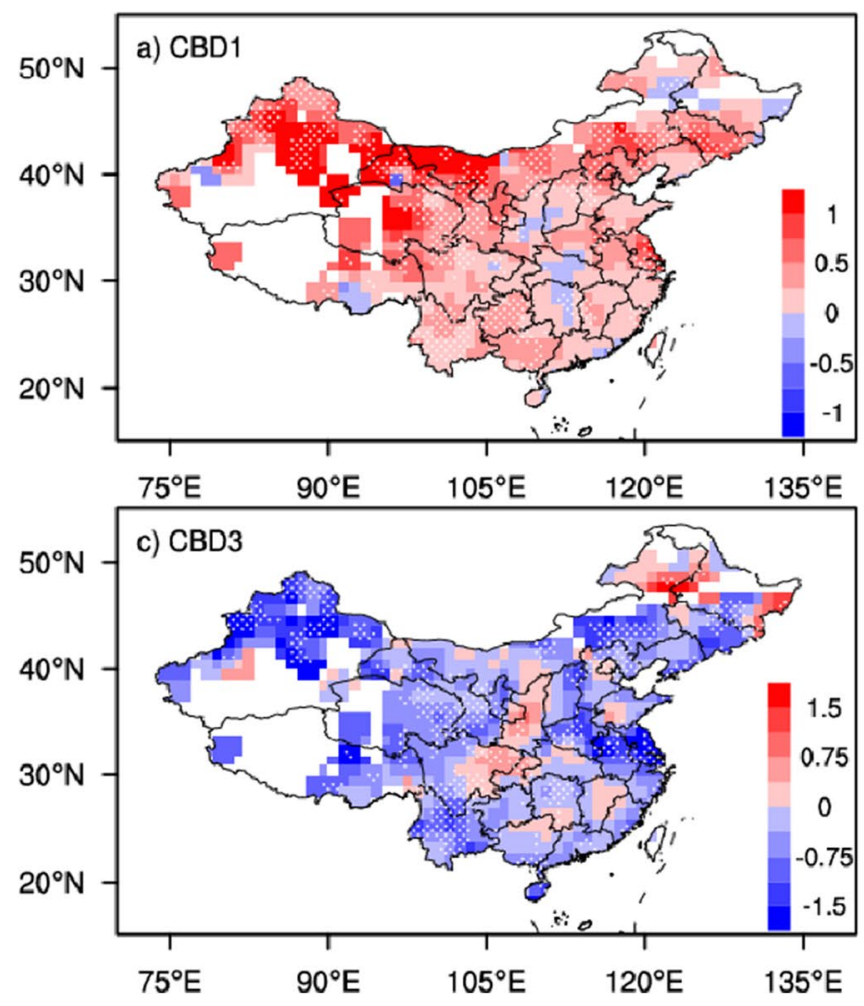

Fig. 3 Observed distributions of trend coefficients (d/y) between 1980 and 2018 in China for (a) CBD1, (b) CBD2, (c) CBD3, and (d) CBD3 in winter; the white dots indicate the grid passing the $95 \%$ confidence level. The boxes overlaid indicate the six representative

from some regions in western China and northeast China, CBD3 displays a coherent significant decreasing trend (more than $82.7 \%$ of, Fig. 3c). A noteworthy downward trend can be found in eastern China, with the minimum value below $-1.18 \mathrm{~d} / \mathrm{y}$.

Among the four seasons, the decrease of CBD3 is most prominent in winter. Fig. $3 \mathrm{~d}$ shows the trend of wintertime CBD3 in China during 1980-2018, which is similar to the trend of annual CBD3. The regional mean winter CBD3 is decreasing at a rate of $-0.11 \mathrm{~d} / \mathrm{y}$ in China, with minimum centers located in northwestern China, southwestern China, and eastern China. These results are consistent with the increase in wintertime air pollution and an obvious increase in winter haze in China (Feng et al. 2020; Lu et al. 2020; Zhang et al. 2020b). In the following section, we focus on analyzing the reasons for the long-term change of wintertime CBD3 in China.

\section{The reasons for wintertime $C B D 3$ change in China}

Four variables considered in our definition, including low cloud cover (LCC), visibility, relative humidity $(\mathrm{RH})$, and non-precipitation day (non-REP) are taken into
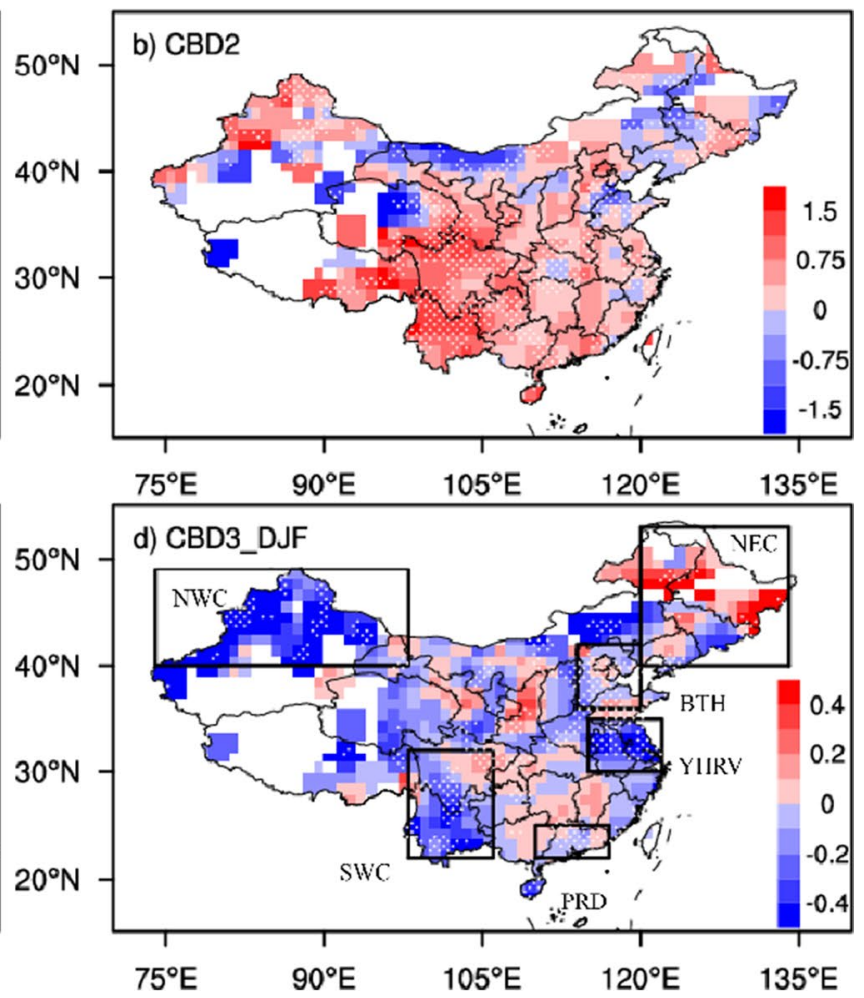

regions, Northeast China (NEC,), Northwest China (NWC), YangtzeHuai River Valley (YHRV), Southeastern China (SWC), Pearl River Delta (PRD), and Beijing-Tianjin-Hebei (BTH)

consideration. The non-REP is calculated by counting the monthly number of non-rainy and non-snow days in winter. Table 1 shows the trend coefficients of selected meteorological variables and their explained variances (Beta square values). According to the $\mathrm{CBD} 3$ definition, there should be a positive relationship between visibility and $\mathrm{CBD} 3$, and a negative one between LCC and CBD3. The RH plays a more complicated role by affecting the optical characteristics of hydrophilic aerosols (Peng et al. 2009; Petters and Kreidenweis 2013).

In China, the growth of non-REP and visibility should contribute to the increase of CBD3. Nevertheless, reduced $\mathrm{RH}$ contributes to the decrease of the dry visibility (below $-0.04 \mathrm{~km} / \mathrm{y}$ ) and finally reduces the CBD3 along with increasing LCC. The changes of RH, non-REP, LCC, and visibility account for $17.39 \%, 9.73 \%, 69.22 \%$, and $1.04 \%$ of the area-mean CBD3 change in China, respectively.

Moreover, we divided China into different sub-regions, including northwest China (NWC), southwest China (SWC), the Yangtze-Huai River Valley (YHRV), Beijing-TianjinHeibei (BTH), Pearl River Delta (PRD), and northeast China (NEC). The locations of these sub-regions are shown in Fig. 2d. In NWC, with the most significant reduction below $-0.45 \mathrm{~d} / \mathrm{y}$, the decrease of CBD3 is dominated by 
Table 1 The trend coefficients of winter CBD3 and the associated meteorological parameters over China and some sub-regions, and the Beta square values are given in the right column (units: \%)

\begin{tabular}{llllll}
\hline Area & CBD3 $(\mathrm{d} / \mathrm{y})$ & $\mathrm{RH}(\% / \mathrm{y})$ & Non-REP $(\mathrm{d} / \mathrm{y})$ & LCC $(\% / \mathrm{y})$ & Visibility $(\mathrm{km} / \mathrm{y})$ \\
\hline China & -0.11 & $-0.06 / 17.39$ & $0.18 / 9.73$ & $0.09 / 69.22$ & $0.018 / 1.042$ \\
YHRV & -0.42 & $-0.03 / 32.06$ & $-0.02 / 0.67$ & $0.05 / 69.89$ & $-0.11 / 3.06$ \\
BTH & -0.02 & $-0.04 / 95.84$ & $0.11 / 53.00$ & $0.03 / 16.98$ & $-0.04 / 3.42$ \\
PRD & 0.02 & $-0.06 / 8.52$ & $0.26 / 15.05$ & $0.18 / 30.14$ & $0.14 / 17.98$ \\
NEC & 0.02 & $-0.07 / 24.30$ & $0.20 / 30.58$ & $0.15 / 0.03$ & $0.14 / 1.99$ \\
SWC & -0.13 & $-0.11 / 14.67$ & $0.32 / 22.00$ & $-0.03 / 92.93$ & $-0.08 / 0.90$ \\
NWC & -0.45 & $-0.00 / 5.95$ & $0.06 / 0.76$ & $0.20 / 46.24$ & $-0.01 / 13.10$ \\
\hline
\end{tabular}

reducing visibility and increasing LCC concurrently, with explained variances over $13.10 \%$ and $46.24 \%$, respectively. In BTH, under unfavorable RH, LCC, and visibility conditions, the growth of non-precipitation days leads to a decreasing trend below $-0.02 \mathrm{~d} / \mathrm{y}$, with a dominant role of RH beyond $95.84 \%$. In YHRV, with unfavorable situations for all variables, an obvious decreasing trend (over -0.42 $\mathrm{d} / \mathrm{y}$ ) is detected. The changes in RH and LCC play a more important role in this region, accounting for $32.06 \%$ and $69.89 \%$ of the variations of CBD3, respectively. In SWC, where there is a unique downward trend (below -0.03\%) of LCC, the decrease of $\mathrm{RH}$ and visibility contribute to a reduced $\mathrm{CBD} 3$

In other regions with a faint increase (over $0.02 \mathrm{~d} / \mathrm{y}$ ) like PRD and NEC, variations of RH, visibility, and non-REP contribute to deep blue days, with a leading role (more than $30.58 \%$ ) of non-REP and LCC (over 30\%) in NEC. It should be mentioned that considering the close relationships among variations of meteorological factors, the combined multiple explained variances may be greater than $100 \%$ due to multicollinearity. Therefore, these results only give reference information; the underlined mechanism should be analyzed by numerical model in the future.

To reveal the long-term variations of $\mathrm{CBD} 3$, we analyze meteorological and environmental factors for the change of visibility, RH, and LCC. Previous studies indicate that meteorological elements could have a crucial impact dynamically and thermodynamically (Zhang et al. 2014; Liu et al. 2017; Huang et al. 2020a; Ma et al. 2020). Therefore, air temperature at $2 \mathrm{~m}(\mathrm{t} 2 \mathrm{~m}), \mathrm{RH}, \mathrm{WS}$, and $K$ index are selected as major local meteorological conditions. The results are shown in Fig. 4a-d. A nationally downward trend of the $K$ index in Qinghai, northwestern Sichuan, and southeastern Tibet can be found in Fig. 4a. A more stable atmospheric stratification in the lower and middle troposphere favors formations of LCC in relatively moist near-surface conditions (Wu et al. 2013; Horton et al. 2014). Meanwhile, the decrease of the $\mathrm{K}$ index should be related to the increase of $\mathrm{t} 2 \mathrm{~m}$ (Fig. 4b) and the decrease of RH (Fig. 4c). And it can partly explain the widespread increasing trend of CBD3, especially in coastal regions, consistent with previous studies (Cai et al. 2017; Li et al. 2018; Pei and Yan
2018). The wind speed also shows a significant decreasing trend in most parts of China (Fig. 4d). Previous studies show that decreasing wind speed can hinder the horizontal transportation of air pollutants (Zhang et al. 2014), which could partly explain the decrease of CBD3.

Earlier works find that through scattering and absorbing function, aerosol extinction can directly deteriorate visibility, and sulfate ammonium, organics, and nitrate ammonium are the largest contributors to the light extinction coefficient in China (Huang et al. 2012; Yang et al. 2012). Meanwhile, anthropogenic aerosols could affect clouds mainly as the most common condensation nuclei $(\mathrm{CNN})$ in environments by altering the microphysical properties of liquid and ice clouds (Bierkens et al. 2001). Additionally, increasing CNN can inhibit low cloud precipitation by weakening the mixedphase stratocumulus (Yun et al. 2009; Qian et al. 2010). As a result, there exists an intimate linkage between anthropogenic aerosols and CBD3. Then, the trend of main precursors of fine particles (including SO2, NOx, and NMVOC) and BC (black carbon), which could affect visibility, are calculated. Only data from 1980 to 2014 are used due to data restriction.

Significant upward trends of $\mathrm{SO}_{2}, \mathrm{NOx}, \mathrm{NMVOC}$, and $\mathrm{BC}$ are shown in Fig. 4e-h displays, with a rate of $0.21,0.21$, 0.12 , and $0.01 \mathrm{Tg} / \mathrm{y}$ during 1980 and 2014 , respectively. The major emission-increasing zones are accompanied by obvious decreasing trends of $\mathrm{CBD} 3$, with the correlation coefficients of $-0.43,-0.46,-0.47$, and -0.51 , all passing the $99 \%$ confidence level. The result reveals a stronger connection between CBD3 and human activity than meteorology at a national scale, and the $\mathrm{BC}$ is the primary emission affecting CBD3 in China.

YHRV, which is the most populous region with the highest emission (at rates over 0.84, 0.84, 0.46, and $0.04 \mathrm{Tg} / \mathrm{y}$ for SO2, NOx, NMVOC, and BC) in China, is found to be the most susceptible region. CBD3 in this region is significantly and negatively related to emissions, with the correlation coefficients all below -0.82 . In NWC, SWC, and BTH, similar situations can be found except for the major role of $\mathrm{BC}$ in $\mathrm{NWC}$ and $\mathrm{SO}_{2}$ for another two, with a correlation coefficient of $-0.39,-0.25$, and -0.16 , respectively. The weak connections might indicate the complicated feedback 

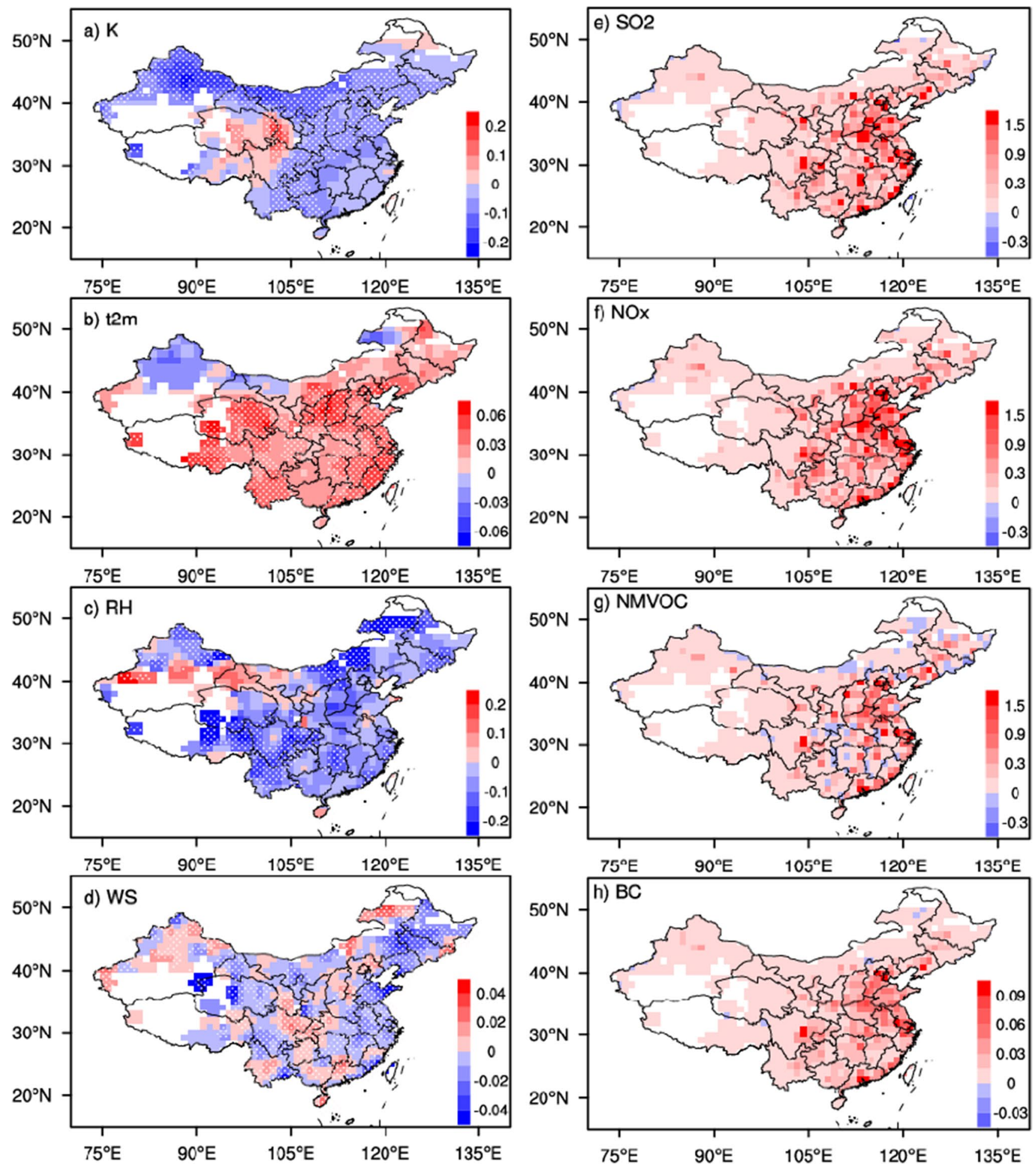

Fig. 4 The spatial distributions of trend coefficients of (a) $\mathrm{K}$ index, (b) $\mathrm{t} 2 \mathrm{~m}\left({ }^{\circ} \mathrm{C} /\right.$ year), (c) relative humidity (\%/year), (d) wind speed $(\mathrm{m} /$ s•year), (e) SO2, (f) NOx, (g) NMVOC, and (h) BC (units Tg/y) from

between aerosols and meteorology, which needs further study. On the contrary, weak correlations in PRD and NEC might indicate a more important role of meteorological
1980 to 2018 in winter. The white dots indicate the grid passing the $90 \%$ confidence level

conditions. We note that the results are probably affected by the limit of the analysis period. Further analysis is needed when the data are extended. 


\section{Conclusions and discussion}

Although blue sky is a common weather phenomena and close to the needs of human, few studies have investigated it specially. In this study, we classify the types of blue sky according to meteorology condition (cloud cover and precipitation) and the concentrations of atmospheric aerosols (atmospheric visibility), and compute their longterm changes in China. It is found that deep blue sky days decrease significantly in China during 1980-2018, especially after 2013. NWC and YHRV share the most obvious downward trend on an annual scale or in winter.

Human activities at least partly contribute to the decrease of winter CBD3 in China. The variations of winter CBD3 are closely related to anthropogenic emissions of $\mathrm{SO}_{2}$, NOx, NMVOC, and $\mathrm{BC}$ with the correlation coefficients of $-0.43,-0.46,-0.47$, and -0.51 , respectively. Meantime, the change of meteorological conditions is also responsible for the decrease of winter CBD3 in this period. The decrease in surface wind speed hinders air pollutant cleaning, and the increase in surface air temperature and decrease in relative humidity favor low cloud genesis, which is adverse to the occurrence of blue sky. These findings suggest that the occurrence of deep blue sky is affected by both the change of meteorological conditions and anthropogenic emissions.

This study only focus on China, but the definition of classified blue sky can extend to the global. Investigating how the blue sky change in the global may help us monitor the change of atmospheric environment of the earth, which deserve further study in the future.

Supplementary Information The online version contains supplementary material available at https://doi.org/10.1007/s00704-021-03898-1.

Author contribution Gang Huang: conceptualization, supervision. Su Wang: methodology, software, writing-original draft, visualization, investigation. Kaiming Hu: writing-original draft, writing-reviewing, and editing, data curation. Lin Wang, Tie Dai, and Chunjiang Zhou: writing - reviewing.

Funding This work was supported by the Second Tibetan Plateau Scientific Expedition and Research (STEP) program (2019QZKK0102), the National Natural Science Foundation of China (41831175, 91937302, 41721004, and 41775086), and the Key Deployment Project of the Centre for Ocean Mega-Research of Science, Chinese Academy of Sciences (COMS2019Q03).

Data availability The meteorological observations are archived by the China Meteorological Administration. The Re-Analysis data are provided by ECMWF. The air emissions species are provided by The Community Emissions Data System (CEDS).

Code availability The code used in this study will be available on reasonable request.

\section{Declarations}

Ethics approval The authors paid attention to the ethical rules in the study. There is no violation of ethics.

Consent to participate All the authors admitted that they have contributed to the study.

Consent for publication If this study is accepted, it can be published in the Theoretical and Applied Climatology journal.

Conflict of interest The authors declare no competing interests.

\section{References}

Alexander LV, Zhang XB, Peterson TC, Caesar J, Vazquez-Aguirre JL (2006) Global observed changes in daily climate extremes of temperature and precipitation. J Geophys Res-Atmos 111:D05109

Alexandersson H, Moberg A (1997) Homogenization of Swedish temperature data. Part I: homogeneity test for linear trends. Int J Climatol 17(1):25-34

Bei N, Li X, Tie X, Zhao L, Wu J, Li X, Liu L, Shen Z, Li G (2020a) Impact of synoptic patterns and meteorological elements on the wintertime haze in the Beijing-Tianjin-Hebei region, China from 2013 to 2017. Sci Total Environ 704:135210

Bei NF, Li XP, Tie XX, Zhao LN, Wu JR, Li X, Liu L, Shen ZX, Li GH (2020b) Impact of synoptic patterns and meteorological elements on the wintertime haze in the Beijing-Tianjin-Hebei region, China from 2013 to 2017. Sci Total Environ 704:12

Bierkens MFP, Dolman H, Troch P (2001) Climate and the hydrological cycle

Cai W, Li K, Liao H, Wang H, Wu L (2017) Weather conditions conducive to Beijing severe haze more frequent under climate?change. Nat Clim Chang 7(4):257-262

Chang L, Wu Z, Xu J (2020) A comparison of haze pollution variability in China using haze indices based on observations. Sci Total Environ 715(May1):136929.1-136929.12

China State Council (2013) Action plan on prevention and control of air pollution. http://www.gov.cn/zwgk/2013-09/12/content_24867 73.htm. Accessed 12 Sep 2013

China State Council (2018) the Three-year Action Plan for Blue-Sky Defense War. http://www.gov.cn/home/2018-07/03/content_53032 11.htm. Accessed 03 Jul 2018

Dai ZJ, Liu DY, Yu K, Cao L, Jiang YS (2020) Meteorological variables and synoptic patterns associated with air pollutions in Eastern China during 2013-2018. Int J Environ Res Public Health 17(7):19

Dee D, Uppala SM, Simmons AJ (2011) The ERA-Interim reanalysis: configuration and performance of the data assimilation system. QJR Meteorol Soc 137:553-597

Ding AJ, Huang X, Nie W, Sun JN, Kerminen V-M, Petäjä T, Su H, Cheng YF, Yang X-Q, Wang MH (2016) Black carbon enhances haze pollution in megacities in China. Geophys Res Lett 43(6):2873-2879 n/a-n/a

Dufour G, Eremenko M, Cuesta J, Doche C, Foret G, Beekmann M, Cheiney A, Wang Y, Cai Z, Liu Y, Takigawa M, Kanaya Y, Flaud JM (2015) Springtime daily variations in lower-tropospheric ozone over east Asia: the role of cyclonic activity and pollution as observed from space with IASI. Atmos Chem Phys 15(18):10839-10856

Easterling DR, Meehl GA, Parmesan C, Changnon SA, Karl TR, Mearns LO (2019) Climate extremes: observations, 
modeling, and impacts. Science (New York, NY) 2000年 289卷 (期(5487)):2068-274页

Fan GF, Ren L, Mao YD (2017) Reconstruction of haze day database based on the comparison between manual and automatic observations. Zhongguo Huanjing Kexue/china Environ Sci 37(4):1254-1261

Fast JD, Gustafson WI, Easter RC, Zaveri RA,Peckham SE (2006) Evolution of Ozone, particulates, and aerosol direct radiative forcing in the vicinity of Houston using a fully coupled meteorologychemistry-aerosol model. J Geophys Res Atmos 111(D21)

Feng J, Liao H, Li YJ, Zhang ZY, Tang YX (2020) Long-term trends and variations in haze-related weather conditions in north China during 1980-2018 based on emission-weighted stagnation intensity. Atmos Environ 240:13

Hoesly RM, Smith SJ, Feng LY, Klimont Z, Janssens-Maenhout G, Pitkanen T, Seibert JJ, Vu L, Andres RJ, Bolt RM, Bond TC, Dawidowski L, Kholod N, Kurokawa J, Li M, Liu L, Lu ZF, Moura MCP, O'Rourke PR, Zhang Q (2018) Historical (17502014) anthropogenic emissions of reactive gases and aerosols from the Community Emissions Data System (CEDS). Geosci Model Dev 11(1):369-408

Horton D, Skinner CB, Singh D, Diffenbaugh NS (2014) Occurrence and persistence of future atmospheric stagnation events. Nat Clim Chang 4(8):698

Hu K, Huang G, Zheng XT, Xie SP, Qu X, Du Y, Liu L (2013) Interdecadal variations in ENSO influences on Northwest Pacific-East Asian early summertime climate simulated in CMIP5 models. J Clim 27(15):5982-5998

Huang K, Zhuang G, Lin Y, Wang Q, Fu Q (2012) Impact of anthropogenic emission on air-quality over a megacity - revealed from an intensive atmospheric campaign during the Chinese Spring Festival. Atmos Chem Physics 12(7):17151-17185

Huang RJ, He Y, Duan J, Li Y, O'Dowd CD (2020a) Contrasting sources and processes of particulate species in haze days with low and high relative humidity in wintertime Beijing. Atmos Chem Phys 20(14):9101-9114

Huang X, Ding A, Gao J, Zheng B, Zhou D, Qi X, Tang R, Wang J, Ren C, Nie W, Chi X, Xu Z, Chen L, Li Y, Che F, Pang N, Wang H, Tong D, Qin W et al (2020b) Enhanced secondary pollution offset reduction of primary emissions during COVID-19 lockdown in China. Natl Sci Rev 8(2):nwaa137

Huang X, Ding A, Wang Z, Ding K, Gao J, Chai F, Fu C (2020c) Amplified transboundary transport of haze by aerosol-boundary layer interaction in China. Nat Geosci 13(6):428-434

Jones PW (1999) First- and second-order conservative remapping schemes for grids in spherical coordinates. Mon Weather Rev 127(9):2204-2210

Kaiser DP (2002) Decreasing trends in sunshine duration over China for 1954-1998: Indication of increased haze pollution. Geophysical Research Letters 29(21)

Kato N, Akimoto H (2007) Anthropogenic emissions of SO2 and NOx in Asia: Emission inventories. Atmos Environ Part A 26(16):2997-3017

Li Z, Folmer H, Xue J (2014) To what extent does air pollution affect happiness? The case of the Jinchuan mining area,China. Ecol Econ 99(mar.):88-99

Li QY, Zhang L, Wang T, Tham YJ, Ahmadov R, Xue LK, Zhang Q, Zheng JY (2016a) Impacts of heterogeneous uptake of dinitrogen pentoxide and chlorine activation on ozone and reactive nitrogen partitioning: improvement and application of the WRF-Chem model in southern China. Atmos Chem Phys 16(23):14875-14890

Li Z, Lau W, Ramanathan V, Wu G, Ding Y, Manoj M, Liu J, Qian Y, Li J, Zhou T (2016b) Aerosol and monsoon climate interactions over Asia. Rev Geophys 54(4):866-929
Li K, Liao H, Cai W, Yang Y (2018) Attribution of anthropogenic influence on atmospheric patterns conducive to recent most severe haze over Eastern China. Geophys Res Lett 45(4):2072-2081

Lin M, Chan IN, Chan CY, Engling G, Bloss W (2012) Implications of regional surface ozone increases on visibility degradation in southeast China. Tellus Series B-Chem Physical Meteorol 64:19625

Liu HR, Liu C, Xie ZQ, Li Y, Huang X, Wang SS, Xu J, Xie PH (2016) A paradox for air pollution controlling in China revealed by "APEC Blue" and "Parade Blue". Sci Rep 6:1-13

Liu HM, Fang CL, Zhang XL, Wang ZY, Bao C, Li FZ (2017) The effect of natural and anthropogenic factors on haze pollution in Chinese cities: a spatial econometrics approach. J Clean Prod 165:323-333

Liu JY, Ren CH, Huang X, Nie W, Wang JP, Sun P, Chi XG, Ding AJ (2020) Increased aerosol extinction efficiency hinders visibility improvement in Eastern China. Geophys Res Lett 47(20):e2020GL090167

Lu SH, Gong SL, He JJ (2020) Uncertainty analysis of spatiotemporal characteristics of haze pollution from 1961 to 2017 in China. Atmos Pollut Res 11(2):310-318

Luechinger S (2010) Life satisfaction and transboundary air pollution. Econ Lett 107(1):4-6

Ma N, Zhao CS, Chen J, Xu WY, Yan P, Zhou XJ (2014) A novel method for distinguishing fog and haze based on PM2.5, visibility, and relative humidity. Sci China-Earth Sci 57(9):2156-2164

Ma SM, Xiao ZM, Zhang YF, Wang LT, Shao M (2020) Assessment of meteorological impact and emergency plan for a heavy haze pollution episode in a core city of the North China Plain. Aerosol Air Qual Res 20(1):26-42

Meinshausen M, Meinshausen N, Hare W, Raper SC, Frieler K, Knutti R, Frame DJ, Allen MR (2009) Greenhouse-gas emission targets for limiting global warming to 2 degrees C. Nature 458(7242):1158-1162

Millar RJ, Fuglestvedt JS, Friedlingstein P, Grubb MJ, Allen MR (2017) Emission budgets and pathways consistent with limiting warming to $1.5^{\circ} \mathrm{C}$. Nat Geosci $10(10): 741-747$

Organization W M (2008) Guide of meteorological instruments and methods of observation. Eos Trans 55

Panmao Z, Sun A, Ren F, Liu X, Gao B, Zhang Q (1999) Changes of climate extremes in China. Clim Chang 42:203-218

Pei L, Yan Z (2018) Diminishing clear winter skies in Beijing towards a possible future. Environ Res Lett 13:124029

Pei L, Yan Z, Sun Z, Miao S, Yao (2018) Increasing persistent haze in Beijing: potential impacts of weakening East Asian winter monsoons associated with northwestern Pacific sea surface temperature trends. Atmos Chem Phys 18:3173-3183

Pei L, Yan Z, Chen D, Miao S (2020) Climate variability or anthropogenic emissions: which caused Beijing Haze? Environ Res Lett 15(3):034004

Peng Y, Pan X, Jie T, Zhou X, Zhang R, Zeng LJP (2009) Hygroscopic growth of aerosol scattering coefficient: a comparative analysis between urban and suburban sites at winter in Beijing. Particuology 7(001):52-60

Petters M, Kreidenweis SM (2013) A single parameter representation of hygroscopic growth and cloud condensation nucleus activity. Atmos Chem Phys 7(8):1081-1091

Pope C, Burnett R, Thun M, Calle E, Krewski D, Ito K, Thurston G (2002) Lung Cancer, cardiopulmonary mortality, and long-term exposure to fine particulate air pollution. JAMA : J Am Med Assoc 287:1132-1141

Qian DY, Gong D, Leung RJASL (2010) Light rain events change over North America, Europe, and Asia for 1973-2009. Atmos Sci Lett 11(4):301-306 
Sun YL, Wang ZF, Wild O, Xu WQ, Chen C, Fu PQ, Du W, Zhou LB, Zhang Q, Han TT, Wang QQ, Pan XL, Zheng HT, Li J, Guo XF, Liu JG, Worsnop DR (2016) "APEC Blue": secondary aerosol reductions from emission controls in Beijing. Sci Rep 6:1-9

Tai A, Mickley LJ, Jacob DJ (2010) Correlations between fine particulate matter (PM2.5) and meteorological variables in the United States: implications for the sensitivity of PM2.5 to climate change. Atmos Environ 44(32):3976-3984

Wang S, Huang G, Lin J, Hu K, Gong H (2019) Chinese Blue days: a novel index and spatio-temporal variations. Environ Res Lett 14(7):074026

Wang J, Liu Y, Ding Y (2020) On the connection between interannual variations of winter haze frequency over Beijing and different ENSO flavors. Sci Total Environ 740:140109

Welsch H (2006) Environment and happiness: valuation of air pollution using life satisfaction data. Ecol Econ 58(4):801-813

Wilks DS, Wilks DL, Wilks DS, Wilks DF, Wilks D, Wilks DL, Wilks D, Wilks D (2006) Statistical methods in the atmospheric science.

Wu D (2004) A discuss on the difference between haze and fog and the warning of brownish haze weather. Guangdong Meteorol 4(1):1-4

Wu P, Christidis N, Stott P (2013) Anthropogenic impact on Earth's hydrological cycle. Nat Clim Chang 3(9):807-810

Xu ZJ, Shan W, Qi T, Gao J (2018) Characteristics of individual particles in Beijing before, during and after the 2014 APEC meeting. Atmos Res 203:254-260

Yang Q, Wang YH, Zhao C, Liu Z, Gustafson WI, Shao M (2011) NOx emission reduction and its effects on ozone during the 2008 Olympic games. Environ Sci Technol 45(15):6404-6410

Yang L, Zhou X, Zhe W, Yang Z, Cheng S, Xu P, Gao X, Wei N, Wang X, Wang WJAE (2012) Airborne fine particulate pollution in Jinan, China: concentrations, chemical compositions and influence on visibility impairment. Atmos Environ 55(Aug.):506-514

Yin Z, Wang H, Chen H (2017) Understanding severe winter haze events in the North China Plain in 2014: roles of climate anomalies. Atmos Chem Phys 17(3):1-27

Yun Q, Gong D, Fan J, Leung LR, Bennartz R, Chen D, Wang W (2009) Heavy pollution suppresses light rain in China: Observations and modeling. Journal of Geophysical Research: Atmospheres 114

Zhai SX, Jacob DJ, Wang X, Shen L, Li K, Zhang YZ, Gui K, Zhao TL, Liao H (2019) Fine particulate matter (PM2.5) trends in China, 2013-2018: separating contributions from anthropogenic emissions and meteorology. Atmos Chem Phys 19(16):11031-11041

Zhang C, Wei Z (2014) Panel estimation for income inequality and CO 2 emissions: a regional analysis in China. Appl Energy 136(C):382-392
Zhang GC, Jiao MY, Li YX (2007) Techniques and methods of contemporary weather forecast (in Chinese). China Meteorological Press, Beijing, p 371

Zhang RH, Li Q, Zhang RN (2014) Meteorological conditions for the persistent severe fog and haze event over eastern China in January 2013. Sci China-Earth Sci 57(1):26-35

Zhang L, Wang T, Lv MY, Zhang Q (2015) On the severe haze in Beijing during January 2013: unraveling the effects of meteorological anomalies with WRF-Chem. Atmos Environ 104:11-21

Zhang L, Shao JY, Lu X, Zhao YH, Hu YY, Henze DK, Liao H, Gong SL, Zhang Q (2016) Sources and Processes affecting fine particulate matter pollution over North China: an adjoint analysis of the Beijing APEC period. Environ Sci Technol 50(16):8731-8740

Zhang L, Liu W, Hou K, Lin J, Song C, Zhou C, Huang B, Tong X, Wang J, Rhine W, Jiao Y, Wang Z, Ni R, Liu M, Zhang L, Wang Z, Yuebin W, Li X, Liu S, Wang Y (2019a) Air pollution exposure associates with increased risk of neonatal jaundice. Nat Commun 10:1-9

Zhang L, Liu W, Hou K, Lin J, Zhou C, Tong X, Wang Z, Yuebin W, Jiang Y, Wang Z, Zheng Y, Lan Y, Liu S, Ni R, Liu M, Zhu P (2019b) Air pollution-induced missed abortion risk for pregnancies. Nat Sustain 2:1011-1017

Zhang Q, Zheng Y, Tong D, Shao M, Hao JJ (2019c) Drivers of improved PM 2.5 air quality in China from 2013 to 2017. Proc Natl Acad Sci 116(49):201907956

Zhang Y, Gao L, Cao L, Yan Z, Wu Y (2020a) Decreasing atmospheric visibility associated with weakening winds from 1980 to 2017 over China. Atmos Environ 224:117314

Zhang Y, Yin Z, Wang H (2020b) Roles of climate variability on the rapid increases of early winter haze pollution in North China after 2010. Atmos Chem Phys 20(20):12211-12221

Zhou T, Gong D, Li J, Li B (2009) Detecting and understanding the multi-decadal variability of the East Asian Summer Monsoon recent progress and state of affairs. Meteorol Z 18(4):455-467

Zhu J, Liao H, Li J (2012) Increases in aerosol concentrations over eastern China due to the decadal-scale weakening of the East Asian summer monsoon. Geophys Res Lett 39(9):9809

Publisher's note Springer Nature remains neutral with regard to jurisdictional claims in published maps and institutional affiliations. 